\title{
Beyond the Circular Economy Theory: Implementation Methodology for Industrial SMEs
}

\author{
Vanessa Prieto-Sandoval ${ }^{1}$ (D), Luz Elba Torres-Guevara ${ }^{* 2}$ iD, Marta Ormazabal $^{3}$ iD, Carmen Jaca $^{3}$ iD \\ ${ }^{1}$ Pontificia Universidad Javeriana, School of Economics and Business (Colombia) \\ ${ }^{2}$ Universidad de La Sabana, International School of Economics and Administrative Sciences (Colombia) \\ ${ }^{3}$ University of Navarra, TECNUN School of Engineering (Spain)
}

julietbv.prieto@javeriana.edu.co, ${ }^{*}$ Corresponding author: luz.torres3@unisabana.edu.co,mormazabal@tecnun.es, cjaca@tecnun.es

Received: November 2020

Accepted: February 2021

\begin{abstract}
:
Purpose: The circular economy has multiple benefits and opportunities to achieve sustainability and a better future for the next generations. The purpose of this paper is to propose a methodology that guides step-by-step any industrial SMEs in the transition from the linear to a circular model. Small and medium enterprises (SMEs) have a crucial role in the sustainable development transition, considering that they represent most of the world's companies.
\end{abstract}

Design/methodology/approach: To develop this methodology, two research techniques were used: a focus group and storyboarding.

Findings: The resulting methodology, called Ecopyme, comprises five steps: 1) Firm identity, 2) Diagnosis, 3) Planning, 4) Get the ball rolling, and 5) Assessment and feedback. In addition, two key criteria that must be included in the whole process were identified: value creation in the firm through a circular economy and organization commitment from the top management to the staff.

Research limitations/implications: The Ecopyme methodology has two limitations: It does not propose either implementation tools or involve consumers and actors at the meso (e.g., eco-industrial parks) and macro (e.g., cities, provinces, countries) levels.

Practical implications: This study will help policymakers understand the SMEs' perspective and remove barriers that may hinder the paradigm shift. The methodology is also a useful tool for consultants and entrepreneurs to incorporate the circular economy (CE) principles into their business.

Originality/value: In the CE literature, little attention has been paid to proposing a structured methodology to implement CE in SMEs. Thus, the study provides a step-by-step methodology that guides any industrial SMEs to transition from linear to circular. Also, it provides additional evidence concerning the importance of human commitment in changing firms' paradigm because people can encourage the adoption of responsible production practices if firms commit CEOs, sustainability managers, and staff.

Keywords: circular economy implementation, strategic management, sustainable improvement, SMEs, storyboarding 


\section{To cite this article:}

Prieto-Sandoval, V., Torres-Guevara, L.E., Ormazabal, M., \& Jaca, C. (2021). Beyond the Circular Economy Theory: Implementation Methodology for Industrial SMEs. Journal of Industrial Engineering and Management, 14(3), 425-. https://doi.org/10.3926/jiem.3413

\section{Introduction}

The current social, economic, and health crisis caused by COVID-19 has reinforced the importance of understanding the multiple benefits and opportunities that Circular Economy (CE) represents to achieve sustainability and a better future for the next generations. This does not mean that it is the only possibility, but it has been widely accepted since 2009, with the launch of the CE Law in China and the European Union Action Plan in 2014 (renewed in 2020) (EU Commission, 2020). Multiple governments, companies, and consumers have seen in the CE a model that allows a closed system in which the infinite use of materials and energy is possible, facilitating economic and social prosperity and avoiding or at least reducing the exploitation of raw materials. Even Pope Francis has been clear about the responsibility that humans have to care for the environment and the adoption of the role of administrators of the planet, instead of owners, through "Laudato Si" (Francis, 2015).

The pandemic period slowed down the linear economy, based on exploiting, transforming, using, and waste resources. Consequently, some essential benefits have been revealed in nature. The Sentinel-5P satellite showed that nitrogen dioxide $\left(\mathrm{NO}_{2}\right)$ pollution caused by fossil fuel combustion has decreased since the pandemic (ESA, 2020). Besides, human isolation allowed the movement and reproduction of species in their natural environment. For example, in Brazil, about 100 endangered hawksbill turtles (Eretmochelys imbricata) managed to hatch on Janga beach, in Pernambuco (Brazil), one of the most popular in the country, taking advantage of the absence of visitors (Phillips, 2020).

Therefore, the CE is viewed as a feasible way to achieve sustainable development by closing the flow of materials and energy (Geissdoerfer, Savaget, Bocken \& Hultink, 2017; Kirchherr, Reike \& Hekkert, 2017) without switching off the global economy. According to Stahel (Stahel, 2016), it "replaces production with sufficiency: reuse what you can, recycle what cannot be reused, repair what is broken, remanufacture what cannot be repaired." Hence, the CE can be described as a systematic approach that requires rethought and transformed the goods and services, which imply the entire life cycle of the products.

The CE can be structured into six fields of action to analyze, diagnose, and help companies transition to the circular paradigm. The fields of action are: 1) take, 2) make, 3) distribute, 4) use/consume, 5) recover, and 6) industrial symbiosis (Jaca, Ormazabal, Prieto-Sandoval, Santos \& Viles, 2018) (Figure 1). Briefly, "take" is related to the origin of natural or technical resources, to choosing them appropriately, and using them effectively to optimize resource use and minimize environmental impacts and costs. "Make" refers to applying manufacturing processes and practices, and consuming resources to create durable goods and services, retain the value of materials and share productive resources. "Distribute" includes logistics activities like transport and distribution to mainly optimizing packing, product size, and routes. "Use and consume" refers to how products should be designed for durability, low resource consumption, ease of updating, and serviceability, if possible. "Recover" is related to where products become materials for other value chains or products' functionality is restored. Finally, "industrial symbiosis" is a transversal field that helps to close the material and energy loops in every field of action by sharing materials, infrastructure, waste, by-products, and materials in general with other organizations (Jaca et al., 2018).

Overall, the literature shows consensus among scholars regarding the multi-level component of the CE, given that it is possible to implement it at different levels, namely the macro, meso, and micro. At the macro-level, CE implementation is carried out by cities, regions, and governments. One of the most remarkable initiatives at the macro-level is the Climate Action Commitment established at COP21 and ratified by the 55 countries that cause 
$47 \%$ of pollution. At the meso-level, implementation involves economic agents integrated into symbiosis, which is flourishing as part of a local economic development strategy in the USA and Europe (Gibbs \& Deutz, 2007) and the China's investment in eco-industrial parks (Zhang, Yuan, Bi, Zhang \& Liu, 2010). Then, the micro-level involves enterprise activities to develop environmental innovations in their product design, cleaner production processes, and offered services (Su, Heshmati, Geng \& Yu, 2013; Yuan, Bi, Moriguichi \& Yuan, 2006). In this level, enterprises and consumers play a key role in the CE implementation (Geng, Fu, Sarkis \& Xue, 2012; Kirchherr et al., 2017; Prieto-Sandoval, Jaca \& Ormazabal., 2018a; Yuan et al., 2006).

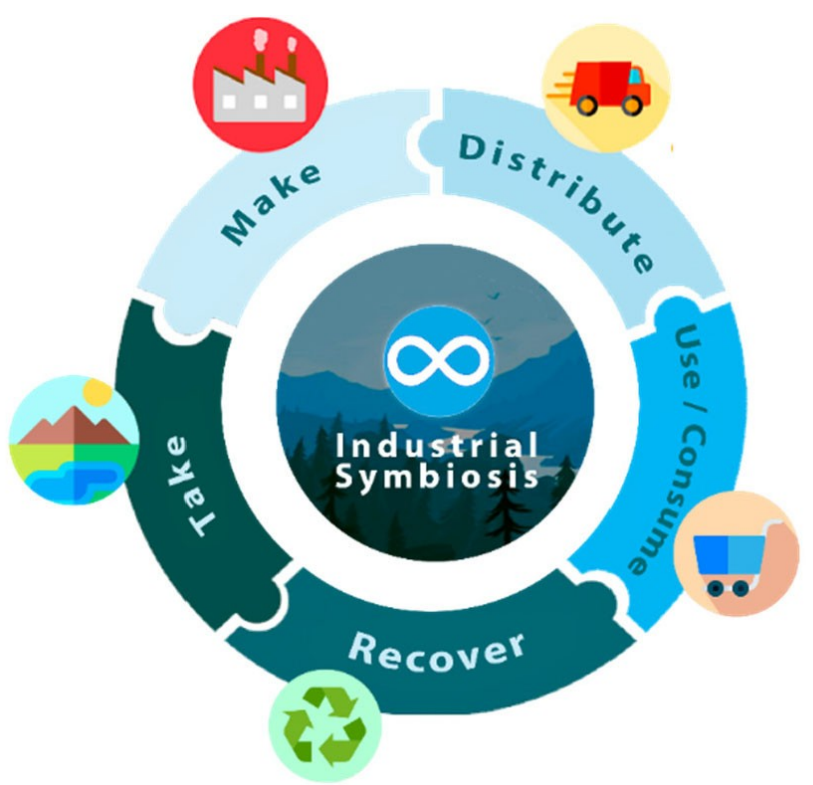

Figure 1. Circular economy fields of action

In particular, the small and medium enterprises (SMEs) are key actors at micro level since they account for $70 \%$ of jobs in the OCDE area (2016). In emerging economies, they contribute up to $45 \%$ of total employment and up to $33 \%$ of national income (GDP) (Teima, Berthaud, Bruhn, De Castro, Joshi, Mirmulstein et al., 2010). Unfortunately, the International Labour Organization (ILO, 2020) estimated that the COVID-19 would cause a rise in global unemployment of between 5.3 million ("low" scenario or best-case) and 24.7 million ("high" scenario or pessimistic). The most vulnerable organizations are the SMEs, given their limited resources and the financial and market barriers they face. Thus, for example, according to Bartik, Bertrand, Cullen, Glaeser, Luca and Stanton (2020), 43\% of 5800 SMEs from the United States are already temporarily closed; on average, the firms reduced their employees by $40 \%$, and $25 \%$ of the SMEs have two months or less in cash in reserve.

Moreover, the managers and owners of SMEs stay far away from developing a clear strategy to transition to the CE paradigm, and the academics and governments must support them now, more than ever. A combined search in November 2020, using "Circular Economy" AND "Implement"* AND "SMEs" or "Small and medium" showed only 22 papers in Web of Science (WoS) and 39 papers in Scopus. This reduced number of papers evidence the need to fill this gap in the literature. In this vein, Korhonen, Nuur, Feldmann and Birkie (2018) discovered a research gap within the $\mathrm{CE}$ implementation in firms, the little-explored themes like organizational culture, strategic thinking and strategy formulation in an organization, organizational inertia or path dependency, organizational transitions, and the resilience of different organizational types, among others. In contrast, Lieder and Rashid (2016) found that the discussion about CE is mainly focused on the resource scarcity and environmental impacts, leaving a gap of knowledge about the CE implementation and its market benefits for industrial actors, specifically on the enterprise level. Likewise, there is still much uncertainty about methods for implementing CE in SMEs, and even prolific academics like Stahel (2016) claim that "Circular-economy knowledge is concentrated in big industries and dispersed across SMEs," such as in the C100 program. Moreover, the CE involves significant challenges for SMEs 
because large companies are not always willing to share information about their waste and by-products to create industrial symbiosis flows.

Given the importance of the CE to deal with resource scarcity, achieve sustainable development and support SMEs at this historical moment, it is essential to develop a methodology that brings companies to this paradigm shift and closer to their strategic purposes in the creation and capture of value in the market. Bearing this in mind, this study aims to propose a methodology that guide step-by-step the SMEs in the transition from the linear to a circular model. Thus, this research seeks to address the following question: What steps and criteria should SMEs follow to strategically implement the CE?

This paper is divided into five parts. Section 2 presents a literature review about the current approaches for implementing CE and creating value. Section 3 explains the methodology used for this research. Section 4 aims to explain the proposed circular economy methodology, and finally, section 5 presents conclusions and, theoretical and managerial contributions.

\section{Literature Review: Approaches for Implementing the $\mathrm{CE}$ and Creating Value}

In the literature, little attention has been paid to proposing a structured methodology to implement the CE in SMEs. Most environmental management systems follow the Plan-Do-Check-Act cycle proposed by Deming (1992) since it is a traditional and well-known way to make all kinds of improvements in firms, and it is associated with environmental management standards. In this line, the "EMAS Cluster Approach" is described by Daddi and Iraldo (2015) as a practical pathway for improving the environmental performance of companies, including SMEs, which belong to a regional cluster or industrial park.

Although some research has been carried out on CE implementation through the business model innovation (e.g., Linder \& Williander, 2017), only a few studies have attempted to investigate the specific pathway that firms follow to make the transition towards the CE (Table 1).

One such study is the Flash Eurobarometer 441 (European SMEs and the circular economy), which was conducted in the $28 \mathrm{EU}$ Member States in April 2016, opened the door to interpreting the behavior of SMEs in the CE framework, in light of studies by authors like Bassi and Dias (2019) and Garcés-Ayerbe et al. (2019). So, for example, according to the latter authors, the "CE behavior is a gradual process" that includes three stages: 1) implementing material recycling and reuse measures, 2) using measures to minimize power consumption and improving product design, and 3) the most proactive SMEs are applying measures to rethink water use and turning to renewable energy (Garcés-Ayerbe et al., 2019). Those studies, however, explore the current or past behavior of the SMEs; but they do not explain in detail how firms may follow those steps to address all the CE fields of action; even these steps do not present enough information about the role of internal and external factors towards achieving the CE in SMEs.

In the literature, a significant number of studies have explored in depth the different circular business models (Antikainen \& Valkokari, 2016; Kirchherr et al., 2017; Linder \& Williander, 2015). Nußholz (2017, 2018), for example, explains that business model innovation facilitates alignment between the value creation logic of the company and the circular strategies for closing the loop of energy and materials. Thus, thinking in terms of the "business model canvas" (Osterwalder \& Pigneur, 2010), this author states that firms should rethink how an organization "creates, delivers, and captures value" throughout the product lifecycle with less environmental impact and within the CE framework. In this sense, Nußholz (2018) proposes a circular business model mapping tool that is especially useful for companies that enable multiple cycles of materials to use and to extent the product's life. However, it is limited when presenting a linear to circular transition route.

Other authors, such as Urbinati, Chiaroni and Chiesa (2017), state that circular business models should be analyzed under two dimensions: 1) the value network related to the key processes and products and 2) the customer value proposition, which is the unique combination of product, price, service, relationship and image that a company offers to the target customer (Kaplan \& Norton, 1996). Ünal et al. (2019), for their part, claim that these two dimensions have to interact to allow the effective transfer of value simultaneously, while Schenkel, Caniëls, Krikke and van der Laan (2015) suggest that value can be manifested in tangible and intangible benefits for multiple actors, 
such as manufacturers, customers, suppliers and the environment and society at large. Additionally, Ünal et al. (2019) point out the importance of organizational commitment to supporting value creation and capture because managers usually face trade-offs between the business's profitability and circularity in the short term. In the case of SMEs, managers are usually the company owners, so they can make strategic decisions about adopting the CE in the firm (Rizos, Behrens, van der Gaast, Hofman, Ioannou, Kafyeke et al., 2016). Thus, if the corporate strategy aims to build an environmentally conscious company, this may motivate employees to develop environmental awareness (Harvey, Bosco \& Emanuele, 2010; Rizos et al., 2016).

\begin{tabular}{|c|c|c|c|c|}
\hline $\begin{array}{c}\text { Level of } \\
\text { implementation }\end{array}$ & CE implementation contributions & $\begin{array}{l}\text { Structured } \\
\text { step-by-step } \\
\text { methodology }\end{array}$ & Authors & Research method \\
\hline Macro & 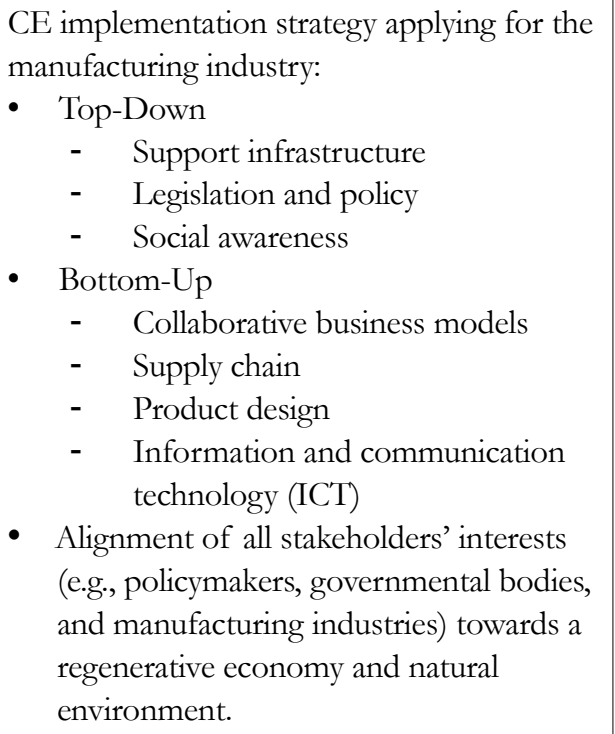 & No & $\begin{array}{l}\text { Lieder \& Rashid } \\
\text { (2016) }\end{array}$ & $\begin{array}{l}\text { Systematic literature } \\
\text { review }\end{array}$ \\
\hline Meso & $\begin{array}{l}\text { - Evidence about the improvement of the } \\
\text { firms' environmental performance } \\
\text { through the EMAS cluster approach. }\end{array}$ & $\begin{array}{l}\text { EMAS Cluster } \\
\text { Approach }\end{array}$ & $\begin{array}{l}\text { Daddi \& Iraldo } \\
\text { (2015) }\end{array}$ & Case study \\
\hline \multirow[t]{4}{*}{ Micro } & - $\quad$ CBM represents a higher investment risk. & No & $\begin{array}{l}\text { Linder \& } \\
\text { Williander (2015) } \\
\text { Antikainen \& } \\
\text { Valkokari (2016) } \\
\text { Kirchherr, Reike } \\
\text { \& Hekkert (2017) }\end{array}$ & Case study \\
\hline & $\begin{array}{l}\text { - Value creation, delivery, and capture } \\
\text { through circular economy. } \\
\text { - Visual tool for business model } \\
\text { transformation. }\end{array}$ & $\begin{array}{l}\text { Yes. The circular } \\
\text { business model } \\
\text { mapping tool }\end{array}$ & $\begin{array}{l}\text { Nußholz (2017, } \\
\text { 2018) }\end{array}$ & $\begin{array}{l}\text { Comparative case } \\
\text { studies and } \\
\text { workshops }\end{array}$ \\
\hline & $\begin{array}{l}\text { - Barriers and enablers to implementing } \\
\text { CE in SMEs. }\end{array}$ & No & $\begin{array}{l}\text { Rizos, Behrens, } \\
\text { van der Gaast, } \\
\text { Hofman, } \\
\text { Ioannou, } \\
\text { Kafyeke et al. } \\
(2016)\end{array}$ & $\begin{array}{l}\text { Literature review } \\
\text { and analysis of a } \\
\text { sample of SMEs } \\
\text { case studies from } \\
\text { GreenEcoNet }\end{array}$ \\
\hline & $\begin{array}{l}\text { - The validity and importance of the } \\
\text { barriers that threaten the } \\
\text { implementation of CD in SMEs. } \\
\text { - CE behavior is a gradual process }\end{array}$ & $\begin{array}{l}\text { Yes. Three steps } \\
\text { are identified as } \\
\text { usual by the } \\
\text { study does not }\end{array}$ & $\begin{array}{l}\text { Garcés-Ayerbe, } \\
\text { Rivera-Torres, } \\
\text { Suárez-Perales \& } \\
\text { Hiz (2019) }\end{array}$ & $\begin{array}{l}\text { Empirical study: } \\
\text { Survey and data } \\
\text { analysis. }\end{array}$ \\
\hline
\end{tabular}




\begin{tabular}{|c|c|c|c|c|}
\hline $\begin{array}{c}\text { Level of } \\
\text { implementation }\end{array}$ & CE implementation contributions & $\begin{array}{l}\text { Structured } \\
\text { step-by-step } \\
\text { methodology }\end{array}$ & Authors & Research method \\
\hline & $\begin{array}{l}\text { - } \quad \text { Implementing material recycling } \\
\text { and reuse measures. } \\
\text { - Using measures to minimize power } \\
\text { consumption and improving } \\
\text { product design. } \\
\text { - } \quad \text { Applying measures to rethink water } \\
\text { use and turning to renewable } \\
\text { energy. }\end{array}$ & $\begin{array}{l}\text { suggest any } \\
\text { instruction to } \\
\text { follow them. }\end{array}$ & & \\
\hline & $\begin{array}{l}\text { - A set of relevant managerial practices } \\
\text { companies. }\end{array}$ & No & $\begin{array}{l}\text { Ünal, Urbinati \& } \\
\text { Chiaroni (2019) }\end{array}$ & Single case study \\
\hline
\end{tabular}

Table 1. Summary of pathways analyzed in the literature for the CE implementation in SMEs

\section{Methodology}

To answer the research question, two research techniques were used: a focus group and storyboarding. The focus group is a research method that allows participants to discuss a topic under the guidance of a researcher or facilitator (Krueger \& Casey, 2008); in this case, the topic was the design of the steps for implementing the CE. It is a valuable tool for getting detailed information on collective views on a subject, but it is more critical for discovering the meanings that underlie participants' perspectives. It is also useful for obtaining a rich understanding of their experiences and beliefs about the discussion topic (Doody, Slevin \& Taggart, 2012; Morgan, 1997).

The storyboarding, for its part, is a narrative and visual pedagogical tool that aids in the creation of a story through a series of pictures, with or without commentary (Dexter, 2016). It helps people create and propose likely stages or situations and outlines a pathway to address those situations by overcoming the possible barriers set up along the route (Forsha, 1994). We used this technique because it allows the participants to imagine what kind of actions, resources, and capabilities they should consider to transform a linear company and what steps they would follow. Besides, creating scenarios provides a context for a specific situation or subject and facilitates a way to plan how to face them (Ramirez, Mukherjee, Vezzoli \& Kramer, 2015). In terms of this study's aim, each picture would represent the experts' visions of each step of the "ideal" methodology.

Nineteen participants were invited to the focus group: however, only eleven accepted (58\%). Worth mentions an adequate number of participants since this method usually requires between eight and twelve people (Saunders, Lewis \& Thornhill, 2009). The group consisted of experts in sustainability and CE. Four were affiliated with recognized universities and one sustainability manager with a leading sustainable cosmetics and personal care firm; two were industrial entrepreneurs, and four were sustainability consultants. The two moderators were experts on environmental management, common-pool resources, the circular economy, eco-innovation, and sustainable development.

The focus group was held in Bogotá (Colombia), it was recorded on a video camera, and additionally, there was an assistant who took notes throughout the workshop. As soon as all participants arrived, they were divided into three groups, considering each participant's experience on environmental management, eco-innovation, and circular economy, age, and professional sector to ensure diversity and gender balance in each group. Each group had at least one male and one female and one researcher, one practitioner, and one consultant. Three activities were completed during the session: 1) Introduction, 2) Storyboarding process, and 3) Discussion for consensus.

1. Introduction: At the beginning of the session, the moderators summarized the CE concept, the relevance of its implementation in firms, and its associated challenges and opportunities, especially in SMEs. This activity took 20 minutes. 
2. Storyboarding process: The three groups were asked to develop a storyboard based on the question: What are the steps in the process of implementing the CE in an SME? Each group had 30 minutes to discuss the question and to define the steps for implementing the CE in an SME. This storyboarding was carried out in four steps: i) Draw a picture to illustrate each of the proposed steps, ii) Give a name to each the picture, to give identity to that idea, iii) Describe clearly the objectives and characteristics of each step, and iv) Share and explain in detail the steps that they had defined. One group proposed four steps, another proposed five, and yet another proposed twelve. However, this difference centered on the level of detail in the description of the methodology. Additionally, the participants suggested some key questions that should be answered in every stage of CE implementation.

3. Discussion for consensus: During this process, the moderators guided the discussion, and they built the final storyboard on a whiteboard with each of the steps proposed by the participants during the activity. As soon as every group had shared its ideas, the moderators invited them to reach consensus by discussing each step's relevance and characteristics, analyzing repeated activities, and defining a meaningful title for each step.

Finally, all audio-visual and written materials collected from the focus group were reviewed to gain a better understanding of the participants' opinions and recover missed information or additional characteristics of each step.

\section{Results and Discussion}

The methodology proposed for implementing the CE in firms is called "Ecopyme methodology". We use this name because in the Spanish-language "pyme" is the equivalent to SME. It includes five steps: 1) Firm identity, 2) Diagnosis, 3) Planning, 4) Get the ball rolling, and 5) Assessment and feedback (Figure 2). It is important to state that these steps are represented cyclically because it is an iterative process that must be addressed continuously to achieve the transition of companies towards CE. In addition, is proposed a set of key questions (Table 2) that aim to guide each step's purpose and give additional support to companies, entrepreneurs, and consultants who wish to implement the EC. Besides, two key transversal aspects are analyzed as transversal components: value creation in the firm through a circular economy and the firm's human commitment, from the leaders of the organization to the staff.

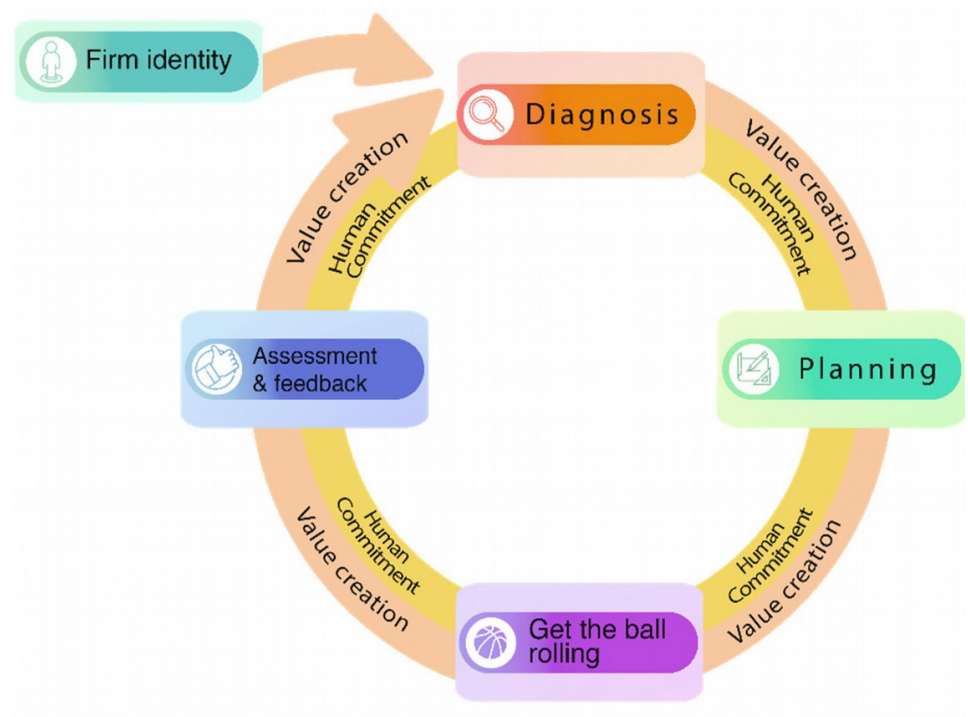

Figure 2. The Ecopyme as a strategic methodology for implementing the CE in SMEs 


\begin{tabular}{|c|c|}
\hline Step & Guidance questions proposed by the experts \\
\hline Firm identity & $\begin{array}{l}\text { 1. Who am I as a firm? } \\
\text { 2. Are the managers ready to change? } \\
\text { 3. Do managers and employees feel environmental awareness? } \\
\text { 4. What are the expectations regarding CE? }\end{array}$ \\
\hline Diagnosis & $\begin{array}{l}\text { 5. What is my starting point? } \\
\text { 6. What is the CE level of implementation? } \\
\text { 7. What resources and capabilities does the company have? } \\
\text { 8. Are the employees trained to be part of the change? } \\
\text { 9. What is the firm's value proposition? } \\
\text { 10. How should the value proposition be improved through CE? }\end{array}$ \\
\hline Planning & $\begin{array}{l}\text { 11. What are the strategic goals? } \\
\text { 12. How are the strategic goals going to be reached? } \\
\text { 13. Who are the leading people or "insiders" in the firm? } \\
\text { 14. What is the potential value of the waste or by-products? } \\
\text { 15. Who are the assisters and resistors? }\end{array}$ \\
\hline Get the ball rolling & $\begin{array}{l}\text { 16. What are the tools and indicators for measuring progress? } \\
\text { 17. What are the new circular business model opportunities? }\end{array}$ \\
\hline Assessment and feedback & $\begin{array}{l}\text { 18. How has the firm progressed? } \\
\text { 19. Were the goals achieved? } \\
\text { 20. What is the best way to communicate the value proposition? } \\
\text { 21. How to move forward? }\end{array}$ \\
\hline
\end{tabular}

Table 2. Questions that companies must answer for implementing the circular economy

The five steps of the methodology, and the most relevant points to consider when applying them, are explained below.

\subsection{Firm Identity}

In this step, the participants agreed that a firm must understand not only what kind of company it is, the portfolio of goods and services that it has, its available resources and its capabilities, but also the external environment in which it is immersed. Likewise, it must explore the concept of the CE to know if it is worth trying to innovate and start the transition from the linear paradigm.

Participants emphasized the need for "Human Commitment," defined by them as the manager or owner's understanding of the CE's concept and the affiliation to the firm's values. The importance of human commitment has been identified in other fields such as corporate social responsibility by recognizing that manager values motivate the value creation for society (Stachowicz-Stanusch \& Amann, 2017: page 98) and inspire the whole organization to be sustainable, which also can bring economic benefits (Chassé \& Courrent, 2018).

It generates commitment (implementation intention), so the $\mathrm{CE}$ concept can be introduced throughout the company strategy. In this vein, the focus group participants explained that commitment might come from 1) the senior manager, 2) the environmental or sustainability manager, and 3) staff aware of ecological or social issues.

Participants stressed the importance of the owner or manager feeling identified with the CE because this generates commitment and interest in implementation, but it could also permeate all levels of the company and keep time and resources from being wasted. This environmental awareness may be voluntary or pushed by legislation or to create competitive advantages.

\subsection{Diagnosis}

This stage aims to identify the firm's challenges and opportunities for creating and capturing value from CE implementation. New value creation opportunities may come from recirculating its "waste" into its processes, sharing material flows, or selling by-products (Patwa, Sivarajah, Seetharaman, Sarkar, Maiti \& Hingorani, 2020; 
Pieroni, McAloone \& Pigosso, 2019). This also accords with our earlier observations, which showed that firms might find CE opportunities by analyzing themselves according to the six fields of action (take, transform, distribute, use/consume, recover, and industrial symbiosis) (Prieto-Sandoval, Ormazabal, Jaca \& Viles, 2018b).

Furthermore, in this step is key to making an internal and external diagnosis because it has the potential to unveil some CE practices and CE failures. This allows firms to compare their results against other similar firms and sustainable firms that belong to their industrial sector and analyze their business environment. These results are in line with our previous work and the research developed by Del Rio et al. (Del Río, Carrillo-Hermosilla, Könnölä \& Bleda, 2016) by confirming that the ease of making the paradigm change will depend on the organization's internal factors (resources, capabilities, competences and dynamic capabilities) and the pressure from external factors, like consumers, governments, suppliers, and competitors, depending on the firm's position in the market. Another key element that needs to be considered is the human talent, because the firm may be wasting capabilities or skills that could be used in CE processes, such as people with experience or studies related to environmental and sustainability management, cleaner production, or eco-innovation.

Additionally, this diagnosis requires support from third parties related to the firm's processes and support activities, such as suppliers, customers, and business associations. Likewise, it would help identify the hidden costs associated with the firm's environmental impact, for example, at the macro-level. Andersen (2007) posited that understanding the economic costs of ecological externalities might support and expand the analysis of the virtues of a more CE.

Finally, the focus group experts suggested that as soon as the firm decides to start the CE model transition, the firm should design accountability strategies to communicate its commitment to becoming sustainable publicly. Such public commitment reduces somewhat the possibility of the firm not continuing with this process.

\subsection{Planning}

Based on our results, in this step, firms must identify the barriers and opportunities for proposing CE strategies, prioritizing them according to the CE fields of action, the corporate strategy, and analyzing their viability. These findings are consistent with those of Ormazabal, Prieto-Sandoval, Puga-Leal and Jaca (2018) and Vermunt, Negro, Verweij, Kuppens and Hekkert (2019), showing that firms would design strategies considering its business model, the human or soft barriers, and hard barriers that may hamper its transition to CE.

In this stage, the firm also should analyze the potential destination of their processes waste since they can be reintroduced in their processes or other value chains to close the cycle. Additionally, the waste should be classified to examine its value or potential use in another company's value chain. This finding has important implications for developing an environment of industrial symbiosis.

Finally, participants noted that firms that plan to make the transition from the linear to the circular paradigm must innovate their profit model and value creation because their product configuration and firm organization will probably change. Furthermore, this phase should include a strategy for improving employees' knowledge of environmental issues and empowering them to lead the CE strategies.

\subsection{Get the Ball Rolling}

In this phase, the action plan for implementing the $\mathrm{CE}$ is carried out. It must constitute a win-win in creating value for the company, the environment, and society. Likewise, it is essential to gather information to build indicators that allow the firm to measure the action plan's success at the end of the CE implementation process. This information should also include data collected from internal and external stakeholders. This will enable the firm to follow its advances and achieve a process of continuous improvement. It is also relevant to identify the new operations and the market niche, as well as the externalities and how the new business model can affect the firm's finances. A set of tools and techniques is necessary for translating the CE from a corporate strategy to the firm's operational level. Moreover, the tools and techniques should be organized according to each CE field of action, and as many of them are free, any SME can use them to overcome the hard or soft barriers that it faces.

Like the previous step, this step is a valuable opportunity to make changes in the business model and prototype sustainable products. Moreover, the firm must define how it will link its activity with other activities in its industrial 
sector or region. Along these lines, the focus group participants stressed that technologies related to Industry 4.0, such as the Internet of Things (IoT), Big Data, and cloud computing, could simplify CE implementation and help firms to integrate their material flows with other stakeholders. This finding agrees with Tseng et al. 's (Tseng, Tan, Chiu, Chien \& Kuo, 2018) paper, which explains the potential of Industry 4.0 in achieving CE and defines their interrelationship as a gap in the literature on industrial ecology and for the scientific community. Worth mentioning that the human commitment to the environment was continuously mentioned by the participants as a fundamental issue for CE implementation and the willingness to invest time and resources.

\subsection{Assessment and Feedback}

This step represents the end of the cycle. Therefore, it is necessary to evaluate the results according to the previously defined implementation plan and strategies. A communication strategy is vital for informing the internal and external stakeholders about the company's progress and its value proposition. It is a way to be transparent and held responsible to the internal stakeholders, the market, and consumers. Therefore, the firm should recognize its weak environmental aspects, communicate the shortcomings identified in the process, and propose improvement actions and new future goals. The participants believed an ongoing need to identify options for creating value through CE implementation in firms.

\section{Conclusions: Theoretical and Managerial Contributions}

Returning to the question posed at the beginning of this study, this research has several managerial and theoretical applications. Firstly, this study provides evidence that confirms a research gap related to the lack of managerial methodologies for implementing the CE in SMEs. Our review of the literature has uncovered that the last decade researchers were focused on CE theoretical understanding, while the practical applications in firms got low attention.

Second, this study encourages the paradigm shift in enterprises by providing a step-by-step methodology, especially for SMEs, integrated into a strategic methodology for implementing the circular economy in SMEs. This methodology is named Ecopyme and includes five iterative steps: 1) Firm identity, 2) Diagnosis, 3) Planning, 4) Get the ball rolling, and 5) Assessment and feedback. Of course, after the firm has gone through this process one time, the first step is not necessary because the firm has already realized the importance and opportunities of CE.

Although academic studies can show how a new circular business creates, delivers, and captures value, these studies do not show how to transition from linear to circular. Similarly, it happens with the measurements and the CE case studies, since they are a photograph of the result, but do not show the process to achieve the circumstances in the companies. The Ecopyme methodology for implementing the CE has several uses. For example, companies will be able to follow the proposed steps to transition from the linear to the circular economic model. Besides, the iterative process aims to encourage firms to make the transition towards the CE steadily.

At the same time, the focus group showed two transversals criteria that must be included in the whole process: Human commitment and the creation of value through a CE. The present study provides additional evidence concerning the importance of human commitment in changing firms' paradigm because people can encourage the adoption of responsible production practices if firms commit CEOs, sustainability managers, and staff. In this sense, human talent managers will probably see new challenges for recruiting and coaching professionals with environmental knowledge and awareness. At the same time, this study confirms previous findings on the importance of creating value through business model innovation in the CE framework; it also contributes additional evidence that suggests that firms that belong to the linear paradigm should rethink their business models to create value for the environment and society.

From other perspectives, this study will help policymakers understand the firms' perspective and remove barriers that may hinder the development of eco-innovation, sustainable business models, and firms' environmental awareness. Also, the methodology might be a useful tool for consultants to help other firms, especially SMEs, to incorporate the CE principles into their business. 
This research also provides a methodological contribution to the use of storyboarding as a creative problem-solving tool. The storyboarding technique proved to be useful for understanding the CE implementation challenge in SMEs, and it helped to define specific steps to propose a new methodology. This work is evidence of its usefulness to fields of study related to economics and management. However, more research on this topic needs to be undertaken to determine whether this methodology will enable us to design similar methodologies elsewhere in the world.

Finally, some significant limitations need to be considered. First, this methodology could be useful for all types of industrial companies and their departments; however, it is mainly focused on SMEs. Nonetheless, there is significant room for further progress in determining particular methodology implications for each industrial sector. Second, the Ecopyme methodology leaves room for further research on proposing implementation tools and involve consumers and actors at the meso- (e.g., Eco-industrial parks) and macro- (e.g., cities, provinces, countries) levels.

This work's natural progression is to develop future empirical studies on implementing CE in enterprises, especially SMEs. In this sense, companies' transformation, consumer habits, and the trend in government decision-making towards CE is not an easy task. However, there will be no second chance to transform our society and our economy, to live in harmony with nature in our Common Homme.

\section{Acknowledgments}

The authors gratefully acknowledge the experts who participated in the Focus Group for their contributions to making this research possible, especially Prof. Carlos Calderón, who inspired companies and students to contribute to sustainable development until the end of his life.

Likewise, we thank to the Pontificia Universidad Javeriana, Universidad de La Sabana, and University of Navarra for their support and high interest on circular economy implemetation in our society.

\section{Declaration of Conflicting Interests}

The authors declared no potential conflicts of interest with respect to the research, authorship, and/or publication of this article.

\section{Funding}

The article is based on research funded by the Spanish National Programme for Fostering Excellence in Scientific and Technical Research and The European Regional Development Fund: DPI2015-70832-R (MINECO/FEDER), the Project "Desafíos y oportunidades de la implementación de la Economía Circular en las empresas" sponsored by Pontificia Universidad Javeriana ID00009299 and the Project "Implementación de la economía circular en el sector industrial ubicado en la Provincia de Sabana Centro y sus alrededores - EICEA-117-2018" sponsored by Universidad de La Sabana.

\section{References}

Andersen, M.S. (2007). An introductory note on the environmental economics of the circular economy. Sustainability Science, 2(1), 133-140. https://doi.org/10.1007/s11625-006-0013-6

Antikainen, M., \& Valkokari, K. (2016). Framework for sustainable circular business model innovation. The ISPIM Innovation Forum, Boston, MA, USA, 6(7), 5-12. https://doi.org/10.22215/timreview1000

Bartik, A., Bertrand, M., Cullen, Z., Glaeser, E.L., Luca, M., \& Stanton, C. (2020). How are Small Businesses Adjusting to COVID-19? Early Evidence from a Survey. In NBER working papers, 26989.

https://doi.org/10.3386/w26989

Bassi, F., \& Dias, J.G. (2019). The use of circular economy practices in SMEs across the EU. Resources, Conservation and Recycling, 146(April), 523-533. https://doi.org/10.1016/j.resconrec.2019.03.019 
Chassé, S., \& Courrent, J.M. (2018). Linking owner-managers' personal sustainability behaviors and corporate practices in SMEs: The moderating roles of perceived advantages and environmental hostility. Business Ethics, 27(2), 127-143. https://doi.org/10.1111/beer.12176

Daddi, T., \& Iraldo, F. (2015). The effectiveness of cluster approach to improve environmental corporate performance in an industrial district of SMEs: a case study. International Journal of Sustainable Development \& World Ecology, November, 1-11. https://doi.org/10.1080/13504509.2015.1106988

Del Río, P., Carrillo-Hermosilla, J., Könnölä, T., \& Bleda, M. (2016). Resources, capabilities and competences for eco- innovation. Technological and Economic Development of Economy, 22(2), 274-292. https://doi.org/10.3846/20294913.2015.1070301

Deming, W.E. (1900-1993). (1992). Out of the crisis: quality, productivity and competitive position. Cambridge University Press. http://ezproxy.si.unav.es:2048/login?url=http://search.ebscohost.com/login.aspx? direct=true\&AuthType=ip,url\&db=edsnuk\&AN=edsnuk.vtls001460008\&lang=es\&site=eds-live\&scope=site

Dexter, Y. (2016). Nursing Children and Young People Storyboarding as an aid to learning about death situations in children's nurse education. Nursing Cbildren and Young People, 28(5), 16-21. https://www.healio.com/nursing/iournals/ine/2018-5-57-5/\%7B18276bea-13d7-4c60-9623-50fb7652af18\%7D/usingstoryboarding-pedagogy-to-promote-learning-in-a-distance-education-program

Doody, O., Slevin, E., \& Taggart, L. (2012). Preparing for and conducting focus group interviews. British Journal of Nursing, 22(3), 170. https://doi.org/10.12968/bjon.2013.22.3.170

ESA (2020). Air pollution remains low as Europeans stay at home. In The European Space Agency (Issue May). https://www.esa.int/Applications/Observing the Earth/Copernicus/Sentinel$\underline{5 \mathrm{P} / \text { Air pollution remains low as Europeans stay at home }}$

EU Commission. (2020). Circular Economy Action Plan, For a cleaner and more competitive Europe. https://ec.europa.eu/environment/circular-economy/pdf/new circular economy action plan.pdf

Forsha, H.I. (1994). Show Me: The Complete Guide to Storyboarding and Problem Solving. Asq Pr.

Francis, P. (2015). Laudato si: On care for our common home. In Encylical Letter. https://doi.org/10.4324/9781315625546

Garcés-Ayerbe, C., Rivera-Torres, P., Suárez-Perales, I., \& Hiz, D.I.L.D.La. (2019). Is it possible to change from a linear to a circular economy? An overview of opportunities and barriers for european small and medium-sized enterprise companies. International Journal of Environmental Research and Public Health, 16(5). https://doi.org/10.3390/ijerph16050851

Geissdoerfer, M., Savaget, P., Bocken, N.M.P., \& Hultink, E.J. (2017). The Circular Economy - A new sustainability paradigm? Journal of Cleaner Production, 143, 757-768. https://doi.org/10.1016/j.jclepro.2016.12.048

Geng, Y., Fu, J., Sarkis, J., \& Xue, B. (2012). Towards a national circular economy indicator system in China: an evaluation and critical analysis. Journal of Cleaner Production, 23(1), 216-224.

https://doi.org/10.1016/j.jclepro.2011.07.005

Gibbs, D., \& Deutz, P. (2007). Reflections on implementing industrial ecology through eco-industrial park development. Journal of Cleaner Production, 15(17), 1683-1695. https://doi.org/10.1016/j.jclepro.2007.02.003

Harvey, D. M., Bosco, S.M., \& Emanuele, G. (2010). The impact of "green-collar workers" on organizations. Management Research Review, 33(5), 499-511. https://doi.org/10.1108/01409171011041929

ILO. (2020). COVID-19 and the world of work: Impact and policy responses. In ILO Monitor (1st ed., Issue March). http://hdl.voced.edu.au/10707/533608

Jaca, C., Ormazabal, M., Prieto-Sandoval, V., Santos, J., \& Viles, E. (2018). Economía circular - Guía para Pymes. EUNSA. 
Kaplan, R., \& Norton, D. (1996). Linking the balanced scorecard to strategy. California Management Review, 39 (I), 53. https://doi.org/10.2307/41165876

Kirchherr, J., Reike, D., \& Hekkert, M. (2017). Conceptualizing the Circular Economy: An Analysis of 114 Definitions. Resources, Conservation and Recycling, 127(September), 221-232. https://doi.org/10.1016/j.resconrec.2017.09.005

Korhonen, J., Nuur, C., Feldmann, A., \& Birkie, S.E. (2018). Circular economy as an essentially contested concept. Journal of Cleaner Production, 175, 544-552. https://doi.org/10.1016/j.jclepro.2017.12.111

Krueger, R., \& Casey, M.A. (2008). Moderating Skills. In Focus groups a practical guide for applied research (104-128). Sage Publications.

Lieder, M., \& Rashid, A. (2016). Towards circular economy implementation: A comprehensive review in context of manufacturing industry. Journal of Cleaner Production, 115, 36-51. https://doi.org/10.1016/j.jclepro.2015.12.042

Linder, M., \& Williander, M. (2015). Circular Business Model Innovation: Inherent Uncertainties. Business Strategy and the Environment. https://doi.org/10.1002/bse.1906

Linder, M., \& Williander, M. (2017). Circular Business Model Innovation: Inherent Uncertainties. Business Strategy and the Environment, 196, 182-196. https://doi.org/10.1002/bse.1906

Morgan, D.L. (1997). Focus Groups as Qualitative Research. In Sage Publications, 16. https://doi.org/10.4135/9781412984287

Nußholz, J.L.K. (2017). Circular business models: Defining a concept and framing an emerging research field. Sustainability (Switzerland), 9(10), 14-17. https://doi.org/10.3390/su9101810

Nußholz, J.L.K. (2018). A circular business model mapping tool for creating value from prolonged product lifetime and closed material loops. Journal of Cleaner Production, 197, 185-194. https://doi.org/10.1016/j.jclepro.2018.06.112

OCDE. (2016). Education at a Glance 2016. https://doi.org/10.1787/eag-2016-en

Ormazabal, M., Prieto-Sandoval, V., Puga-Leal, R., \& Jaca, C. (2018). Circular Economy in Spanish SMEs: Challenges and Opportunities. Journal of Cleaner Production, 185, 157-167. https://doi.org/10.1016/j.jclepro.2018.03.031

Osterwalder, A., \& Pigneur, Y. (2010). Business Model Generation: A Handbook for Visionaries, Game Changers, and Challengers. In A handbook for visionaries, game changers, and challengers. https://doi.org/10.1523/JNEUROSCI.0307-10.2010

Patwa, N., Sivarajah, U., Seetharaman, A., Sarkar, S., Maiti, K., \& Hingorani, K. (2020). Towards a circular economy: An emerging economies context. Journal of Business Research, September, 1-11.

https://doi.org/10.1016/j.jbusres.2020.05.015

Phillips, T. (2020, March 29). Endangered sea turtles hatch on Brazil' s deserted beaches. The Guardian, 2-5. https://www.theguardian.com/world/2020/mar/29/newborn-endangered-sea-turtles-throng-brazils-deserted-beaches

Pieroni, M.P.P., McAloone, T.C., \& Pigosso, D.C.A. (2019). Business model innovation for circular economy and sustainability: A review of approaches. Journal of Cleaner Production, 215, 198-216. https://doi.org/10.1016/j.jclepro.2019.01.036

Prieto-Sandoval, V., Jaca, C., \& Ormazabal, M. (2018a). Towards a consensus on the circular economy. Journal of Cleaner Production, 179, 605-615. https:/ / doi.org/10.1016/j.jclepro.2017.12.224

Prieto-Sandoval, V., Ormazabal, M., Jaca, C., \& Viles, E. (2018b). Key elements in assessing circular economy implementation in small and medium-sized enterprises. Business Strategy and the Environment, 27(8), 1525-1534. https://doi.org/10.1002/bse.2210

Ramirez, R., Mukherjee, M., Vezzoli, S., \& Kramer, A.M. (2015). Scenarios as a scholarly methodology to produce “interesting research”. Futures, 71, 70-87. https://doi.org/10.1016/j.futures.2015.06.006 
Rizos, V., Behrens, A., van der Gaast, W., Hofman, E., Ioannou, A., Kafyeke, T., et al. (2016). Implementation of circular economy business models by small and medium-sized enterprises (SMEs): Barriers and enablers. Sustainability (Switzerland), 8(11). https://doi.org/10.3390/su8111212

Saunders, M., Lewis, P., \& Thornhill, A. (2009). Research methods for business students (5th ed.). Pearson Education Limited.

Schenkel, M., Caniëls, M.C.J., Krikke, H., \& van der Laan, E. (2015). Understanding value creation in closed loop supply chains - Past findings and future directions. Journal of Manufacturing Systems, 37, 729-745. https://doi.org/10.1016/j.jmsy.2015.04.009

Stachowicz-Stanusch, A., \& Amann, W. (2017). Contemporary Perspectives in Corporate Social Performance and Policy: the Middle Eastern Perspective, 317. https://books.google.de/books?id=KfQDwAAQBAJ\&dq $=$ corporate + social + responsibility $+(C S R)+\& l r=\& h l=i t \& s o u r c e=g b s$ navlinks $\mathrm{s}$

Stahel, W.R. (2016). Circular Economy. Nature, 6-9. https://doi.org/10.1038/531435a

Su, B., Heshmati, A., Geng, Y., \& Yu, X. (2013). A review of the circular economy in China: Moving from rhetoric to implementation. Journal of Cleaner Production, 42, 215-227. https://doi.org/10.1016/j.jclepro.2012.11.020

Teima, G., Berthaud, A., Bruhn, M., De Castro, O., Joshi, M., Mirmulstein, M., et al. (2010). Scaling-Up SME Access to Financial Services in the Developing World. In International Finance Corporation (Issue October). http://www.ifc.org/wps/wcm/connect/bd1b060049585ef29e5abf19583b6d16/ScalingUp.pdf?MOD=AJPERES \%5Cnhttp://documents.worldbank.org/curated/en/2010/10/24160982/scaling-up-sme-access-financial-servicesdeveloping-world

Tseng, M.L., Tan, R.R., Chiu, A.S.F., Chien, C.F., \& Kuo, T.C. (2018). Circular economy meets industry 4.0: Can big data drive industrial symbiosis? Resources, Conservation and Recycling, 131, 146-147.

https://doi.org/10.1016/j.resconrec.2017.12.028

Ünal, E., Urbinati, A., \& Chiaroni, D. (2019). Managerial practices for designing circular economy business models: The case of an Italian SME in the office supply industry. Journal of Manufacturing Technology Management, 30(3), 561-589. https://doi.org/10.1108/JMTM-02-2018-0061

Urbinati, A., Chiaroni, D., \& Chiesa, V. (2017). Towards a new taxonomy of circular economy business models. Journal of Cleaner Production, 168, 487-498. https://doi.org/10.1016/j.jclepro.2017.09.047

Vermunt, D.A., Negro, S.O., Verweij, P.A., Kuppens, D.V., \& Hekkert, M.P. (2019). Exploring barriers to implementing different circular business models. Journal of Cleaner Production, 222, 891-902. https://doi.org/10.1016/j.jclepro.2019.03.052

Yuan, Z., Bi, J., Moriguichi, Y., \& Yuan. (2006). The Circular Economy: A New Development Strategy in China. Journal of Industrial Ecology, 10(1,2), 4-8. https://doi.org/10.1162/108819806775545321

Zhang, L., Yuan, Z., Bi, J., Zhang, B., \& Liu, B. (2010). Eco-industrial parks: national pilot practices in China. Journal Of Cleaner Production, 18(5), 504-509. https://doi.org/10.1016/j.jclepro.2009.11.018

Journal of Industrial Engineering and Management, 2021 (www.jiem.org)

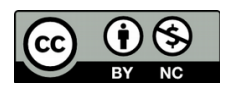

Article's contents are provided on an Attribution-Non Commercial 4.0 Creative commons International License. Readers are allowed to copy, distribute and communicate article's contents, provided the author's and Journal of Industrial Engineering and Management's names are included. It must not be used for commercial purposes. To see the complete license contents, please visit https://creativecommons.org/licenses/by-nc/4.0/. 